\title{
XVIII. Description of a practical diagram for obtaining in a simple and easy manner the correction of the lunar distances as observed by a sextant
}

\author{
Lieut. James Bulkeley
}

To cite this article: Lieut. James Bulkeley (1814) XVIII. Description of a practical diagram for obtaining in a simple and easy manner the correction of the lunar distances as observed by a sextant, Philosophical Magazine Series 1, 44:196, 105-106, DOI: 10.1080/14786441408637421

To link to this article: http://dx.doi.org/10.1080/14786441408637421

曲 Published online: 27 Jul 2009.

Submit your article to this journal $₫$

山l Article views: 2

Q View related articles $\longleftarrow$ 
XVIII. Description of a practical Diagram for oltaining in a simple and easy Manner the Correction of the Lunar Disiances as observed by a Sextant. By Lieut. James Bulketex, of the Royal Navy.

\section{To Mr. Tilloch.}

SIR,-I Take the opportunity of sending you a description of a practical diagram, for obtaining in a simple and easy manner the correction of the lunar distances as observed by a sextant, which is submitted to your approbation and opinion for publication. I am, sir,

$$
\begin{aligned}
& \text { Your obedient servant, } \\
& \text { Huntley-Hall, Cheadle, Staffordshire, JAMEs BulkELEY. } \\
& \text { June } 6,181 \% \text {. }
\end{aligned}
$$

Description. [Plate II. fig. 1.]

$\mathrm{AB}$, a semicircle divided into 180 degrees or equal parts; $\mathrm{AC}$, the semidiameter graduated as a line of sines; $\mathrm{CD}$, a flat bar moveable round the centre of the instrument, and encing with a nonius or pointer to the semicircle, and divided like the semidiameter as a line of sines; EF, a bar sliding at right angles to the semidiameter, and on a pivot, to enable it to fall either to the right or left of the semidianneter, and graduated as a line of chords terminating on the semidiameter with a nonius. $\mathrm{HG}$, a small bar moving at right angles to the moveable radius $C D$, and cutting with a silk thread the perpendicular bar EF, as at I.

\section{Method of using the Instrument.}

Suppose the apparent distance to be $104^{\circ} 30^{\prime}$; the sun's $a p$ parent altitude $43^{\circ} 20^{\prime}$; and the moon's apparent altitude $120^{\prime} 30^{\prime}$; horizontal parallax $57^{\prime} 49^{\prime \prime}$ : to find the true distance. With the moveable radius $C D$ set off the apparent distance on the graduated semicircle $\mathrm{AB} 104^{\circ} 30^{\prime}$ as per nigure. Then with the perpendicular $E F$ set off on the semidiameter $A C$, which is divided as a line of sines, the moon's apparent altitude $12 \cdot 30^{\prime}$, as per figure; and on the radius CD with the sliding perpendicular $\mathrm{CH}$ set off the sun's apparent altitude $43^{\circ} 20^{\prime}$, as per figure: then will the silk thread on GH cut on the perpendicular EF, (which is divided as a line of chords, but the degrees reckoned as minutes, and the minutes as seconds) a number, as $44^{\prime} 00^{\prime \prime}$ at I per figure; which if multiplied by the horizontal parallax, and (as the perpendiculars cut to the right of the semidiameter) divided by 62 , will give a correction to be subtracted fiom the apparent distance, to find the true, as $44^{\prime} 00^{\prime \prime} \times 57^{\prime} 49^{\prime \prime}$ horizontal parallax; and $\div 62=42^{\prime} 26^{\prime \prime}-$ from apparent distance 
Phil.Mag. Tol. XLIV, Pl II .

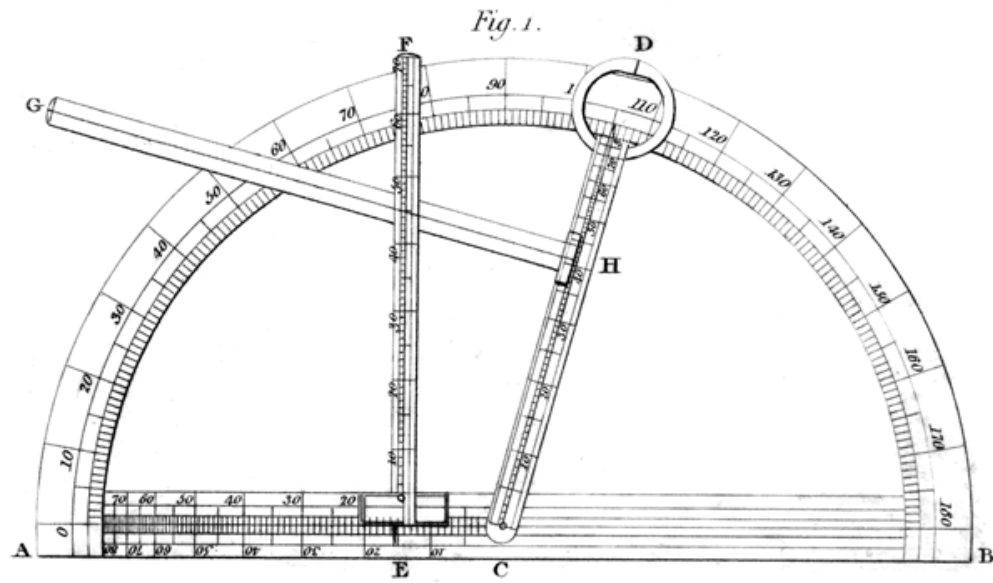

Fig. 2.

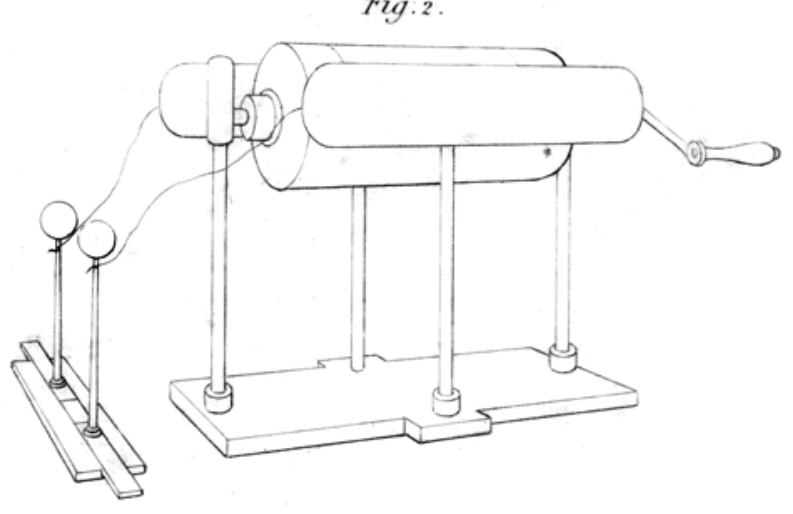

Fig.3.

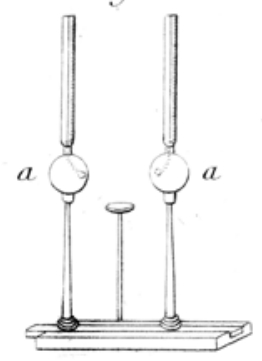


$104^{\circ} 30^{\circ}$, gives the true distance $103^{\circ} 57^{\prime} 34^{\prime \prime}$. But should the perpendiculars cut to the left of the semidiameter, the sum multiplied by the horizontal parallax must be divided by 52 ; and then the correction is to be added to the apparent distance, to find the true distance.

N. B. This instrument may be made either in brass, wood, or with care in card. I made a model in eard, with a radius of about six inches, which gave the true distance within $10^{\prime \prime}$ or $15^{\prime \prime}$ of it when worked by other methods.

\section{Remarks on Mr. Humk's Gazomeler and Blow-pipe. By a Correspondent.}

To Mr. Tilloch.

Tondon, August 13, 1814. Sin, $-U_{\text {PON reading in your Journal for the preceding month, a }}$ paper by Mr. Hume, wherein he describes a method for constructing an improved blow-pipe, out of some chemical apparatus, possessing the peculiar advantage of yielding a current of atmospheric air by inhalation; a suggestion cccurred to me, which upon trial was verified, that too great exertion of the lungs would be required to render the current of air of sufficient duration to be useful in chemical or mineralogical experiments.

The Woulfe's bottle I used for this purpose contained about three pints; and though it required considerable exertion to draw up the water into the separating funnel, yet the stream of air continued only three-quarters of a minute; a time certainly insufficient to make scarcely any experiment.

Now I am inclined to think that the cylindric gazometer, which is almost indispensable to the chemist, and is frequently used for this purpose, answers the end proposed by Mr. Hume more completely than his contrivance; because, merely by raising the interior cylindrical vessel, as nany cubic feet of atmospheric air may be obtained in a given time, as by inhalation we could obtain inches; and with this additional advantage, that the force of the current of air may be increased or decreased at pleasure. Nevertheless, I think that Mr. Hume deserves great credit for endeavouring to increase the powers of the philosophical chemist, without increasing his apparatus, the expense of which already deters many from the pursuit of so pleasing and useful a science. I am, sir, Your most obedient servant, W. W. 